\title{
Effects of maltodextrin on the physical properties of canola oil- based ice creams
}

Nirada Thirathummacoup a,b, Ashari Rozzamri b, Masni Mat Yusoff ${ }^{\text {b* }}$

aFaculty of Agro-Industry, Kasetsart University, 50 Ngamwongwan Road, Ladyao, Chatuchak, Bangkok 10900 Thailand.

${ }^{b}$ Department of Food Technology, Faculty of Food Science and Technology, Universiti Putra Malaysia, 43400, UPM Serdang, Selangor, Malaysia.

\section{ARTICLE HISTORY}

Received: 16 March 2020

Received in revised form: 16 October 2020

Accepted: 2 November 2020

Available Online: 6 November 2020

\section{Keywords \\ Canola oil \\ Fat \\ Ice cream \\ Maltodextrin \\ Physical properties}

\section{Abstract}

Recent trend in production of healthy food products has stimulated ice cream manufacturers to minimize the saturated fat content by replacing it with high-unsaturated fat or oil such as canola oil, yet maintaining the physical properties of the end product. Addition of maltodextrin (MD) into the formulation may assist in obtaining the desirable physical properties. Therefore, the objective of this study was to develop hard ice creams containing different ratios of canola oil and MD. Four ice cream formulations were prepared by weight: MD-0 (5\% oil, $0 \%$ MD), MD-1 (4\% oil, 1\% MD), MD-2 (3\% oil, 2\% MD), and MD-3 (2\% oil, 3\% MD). Both MD-2 and MD-1 exhibited the highest $(45.05 \pm 4.28 \%)$ and the lowest $(32.49 \pm 1.20 \%)$ overrun, respectively, yet there was no significant difference ( $p>0.05$ ) between all ice creams in terms of hardness (3.20-4.79 kg). Additionally, there was no significant difference ( $p>0.05$ ) between MD-0, MD-1, and MD-2 in their melting rates which were significantly slower $(p<0.05)$ than those of MD-3. In overall, decreasing the amount of oil (i.e. increasing amount of MD) resulted in significant $(p<0.05)$ increase in overrun, yet had no significant $(p>0.05)$ effect on the ice cream's hardness and melting rate except for MD-3 for the latter. The ice cream that exhibited the most desirable physical properties was MD-2 (overrun, $45.05 \pm 4.28 \%$; hardness, $3.73 \pm 0.75 \mathrm{~kg}$; slowest melting rate). This finding highlighted the potential of MD in providing desirable texture to the ice creams to certain extent. Future studies are recommended in maintaining the ice cream's flavour and physical properties upon storage, and in determining its sensory acceptability among consumers.

\section{Introduction}

Ice cream is a dairy-based frozen dessert which is highly palatable and desirable among people of different ages, and popular in America, European, and Asian countries. Ice cream is a complex food colloid consisting of air bubbles, fat globules, ice crystals, and an unfrozen serum phase. In ice cream processing, small ice crystals are expected to maintain the product's smooth texture and good palatability for the consumers (Goff, 1997). These attributes are highly affected by the type and amount of fat used in the ice cream.

Milk and fat are the major ingredients in ice cream; thus, the product is rich in calories but poor in some important nutrients such as natural antioxidants, dietary fibres, and minerals. Overconsumption of energy-dense foods, especially high-fat foods (saturated fats) and high-free sugars, is a major cause of obesity (WHO, 2013; 2015). Nowadays, people are more concern and care about their health which lead to consumption of clean and healthy foods. Despite the awareness, it is impossible for everybody to avoid eating desserts, including ice cream. Based on this situation, the ice cream industries are constantly trying to find other alternatives, i.e. a healthier ice cream exhibiting acceptable taste and texture particularly, among consumers. Moreover, they try to change the type of fat in an ice cream from saturated to unsaturated fatty acid in order to lower the risk of elevating low-density lipoprotein (LDL) level which may lead to heart diseases (Erkaya \& Mustafa, 2012; Roller \& Jones, 1996).

Canola oil is wildly known and of great interest nowadays due to presence of high unsaturated fatty acids which may prevent possible heart diseases. The oil contains approximately $6 \% \mathrm{C} 16: 0$ and as high as 58\% cis-C18:1. Ratio of these fatty acids are much higher as compared to that of other common oilseeds (Bayourthe et al., 2000). Additionally, canola oil contributes to lower total cholesterol, lower LDL cholesterol, and lower triglyceride levels by up to $25 \%$. It has very little effects on highdensity lipoprotein (HDL) level (Bierenbaum et al., 2013).

With reference to the benefits of canola oil consumption, it was of great interest to develop hard ice cream based on this oil. However, canola oil is high in unsaturated fatty acids and therefore is not able to form the desirable texture of ice cream. This issue led to this study which formulated low-fat canola oilbased ice creams with addition of maltodextrin at different levels. The maltodextrin bears great potential as a fat replacer in improving the overall quality attributes of the ice cream formulations. Akbari et al. (2019) have critically reviewed the application and functions of fat replacers in low-fat ice cream, and maltodextrin was one of the fat replacers of interest. This was due to its compatibility with solid and liquid fats to form a stable gel, and its minimal negative effects on production, shelf life, and price of final product. Hedayatnia et al. (2016) had also used maltodextrin in reduced-fat coffee creamer. Development of ice cream with reduced fat content and reduced saturated fat content is beneficial in meeting the consumers' demand on healthy food products.

\section{Material and methods}

\subsection{Ice cream preparation}


Table 1 shows the different hard ice cream formulations used in this study which consist of different amounts of canola oil and maltodextrin. All ingredients were purchased from a bakery shop. Maltodextrin 10DE was purchased from Brenntag Sdn. Bhd., Selangor. These formulations were modified from the hard ice cream formulation reported by Rolon et al., (2017), while the processing steps involved were based on the method performed by Lu et al. (2014), Grossi et al. (2011), and Soukoulis et al. (2010), with some modifications. Dry ingredients were combined, added with the water, and slowly heated to $55-60{ }^{\circ} \mathrm{C}$ with continuous stirring. The mixture was further heated to 63 ${ }^{\circ} \mathrm{C}$ and hold at this temperature for 30 min for pasteurization purpose. Next was homogenizing (Silverson Machines Ltd., UK) of the pasteurized mixture for $30 \mathrm{~min}$, followed by ageing in a cold room at $4{ }^{\circ} \mathrm{C}$ for $4 \mathrm{hr}$ and freezing in a hard-served ice cream maker (Taylor $®$, Model 152-40, USA) prior to extrusion into containers at $-5{ }^{\circ} \mathrm{C}$. The ice cream was kept for hardening in a blast freezer at $-25{ }^{\circ} \mathrm{C}$, and further storage was done at $-18{ }^{\circ} \mathrm{C}$ prior to analysis.

\subsection{Determination of overrun}

After the ageing step, the ice cream mix was filled into a cup of pre-determined weight and the mass of the ice cream mix was recorded. This step was repeated for the hard ice cream after the freezing step, prior to packaging. Triplicate readings were taken for each ice cream formulation, and the overrun was calculated according to the Equation (1) by Jimenez-Florez et al. (1993).

\section{Overrun (\%)}

$=\left[\frac{\text { Volume of ice cream }- \text { Volume of ice cream mix }}{\text { Volume of ice cream mix }}\right]$

$$
\times 100
$$

\subsection{Textural properties - Hardness}

Hardness of the ice cream samples was determined after storage, according to the method done by Kurt et al. (2016). Texture Analyzer (TA-XT2i Texture Analyzer, Stable Micro System, Surrey, UK) and the software Exponent 32 (version 6.0.5.0, 2011) were used, equipped with a cylindrical probe (5 $\mathrm{mm}$ diameter) attached to a $30 \mathrm{~kg}$ load cell. The penetration depth at the geometrical centre of the samples was $15 \mathrm{~mm}$, and the penetration speed was set at $2.0 \mathrm{~mm} \mathrm{~s}^{-1}$. The Young's modulus was calculated from the slope of the linear region in the stress-strain curve. The force-deformation curves offered the maximum force as a measure of hardness (positive) and stickiness (negative). All experiments were performed in triplicates.

\subsection{Melting properties}

This method was performed with reference to Biasutti et al. (2013), Karaca et al. (2009), and Soukoulis et al. (2008). The ice cream sample was cut into a similar cylinder form and positioned on a wire mesh (with $2 \mathrm{~mm}$. square openings) at room temperature as shown in Figure 1. The melting rate was determined from the time required for the first drip of the melted ice cream to be observed. The melted ice cream was collected and weighed by using an analytical balance (MettlerToledo, USA) at every $5 \mathrm{~min}$ for $35 \mathrm{~min}$. The percentage of melted ice cream (at every $5 \mathrm{~min}$ ) was determined according to the following Equation (2).

$$
\begin{aligned}
& \text { Percentage of melted ice cream (\%) } \\
& =\left[\frac{\text { Amount of melted ice cream }(\mathrm{g})}{\text { Initial ice cream mass }(\mathrm{g})}\right] \times 100
\end{aligned}
$$

\subsection{Statistical analysis}

All statistical analyses in this study were done by using Microsoft $\AA$ Excel for mac Version 15.40 (171108). Calculation by one-way analysis of variance (ANOVA) with Tukey's multiple comparison test was applied for the determination of significant differences (0.05 significance level) involving more than two samples with each sample analysed in triplicates.

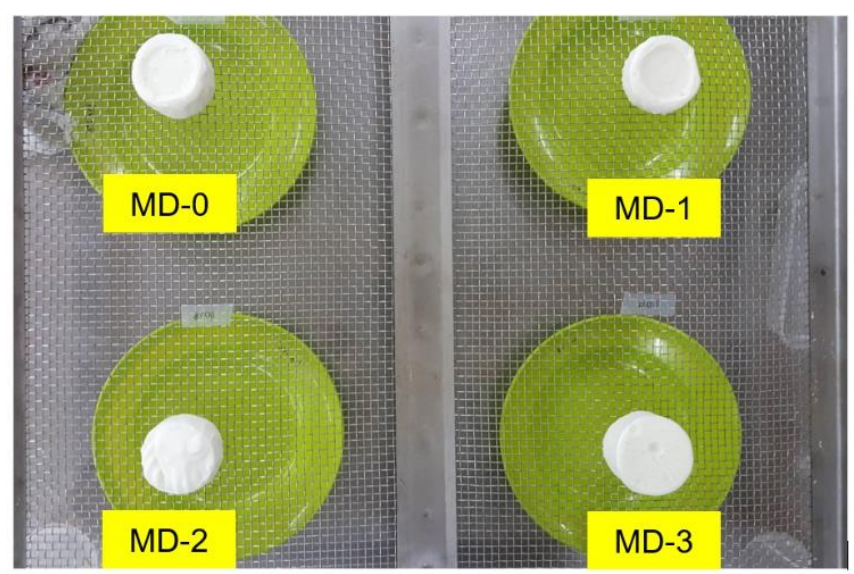

Figure 1. Experimental set up for determination of melting rate of canola oil-based ice cream samples formulated by using different amounts of maltodextrin. MD-0, MD-1, MD-2, and MD3 represent ice creams with $0 \%, 1 \%, 2 \%$ and $3 \%(\mathrm{w} / \mathrm{w})$ maltodextrin, respectively

Table 1. Hard ice cream formulations

\begin{tabular}{lllll}
\hline \multirow{2}{*}{ Ingredients } & \multicolumn{2}{l}{ Amount $(\% \mathrm{w} / \mathrm{w})$} & & \\
\cline { 2 - 5 } & MD-0 & MD-1 & MD-2 & MD-3 \\
\hline Canola oil & 5.0 & 4.0 & 3.0 & 2.0 \\
Maltodextrin 10DE & 0.0 & 1.0 & 2.0 & 3.0 \\
MSNF (Skimmed milk) & 10.0 & 10.0 & 10.0 & 10.0 \\
Sucrose & 15.0 & 15.0 & 15.0 & 15.0 \\
Guar gum \& Carrageenan & 0.5 & 0.5 & 0.5 & 0.5 \\
Corn syrup solids 36DE & 4.0 & 4.0 & 4.0 & 4.0 \\
Water & 65.5 & 65.5 & 65.5 & 65.5 \\
\hline Total & 100.0 & 100.0 & 100.0 & 100.0 \\
\hline
\end{tabular}

MD, maltodextrin; MSNF, milk solid non-fat; DE, dextrose equivalent.

MD-0, MD-1, MD-2, and MD-3 contain 0\%, 1\%, 2\%, and 3\% (w/w) maltodextrin, respectively. 


\section{Results and discussion}

\subsection{Overrun}

Overrun of the ice cream samples was determined by measuring their air-holding ability which increased with the increase in ice cream's volume. The amount of air combined with the mixed ice cream changes the eating characteristics of the ice cream. Lower amount of overrun results in heavier, denser, and colder ice cream, while higher amount of air results in creamier and lighter ice cream texture (Gunstone \& Padley, 2018).

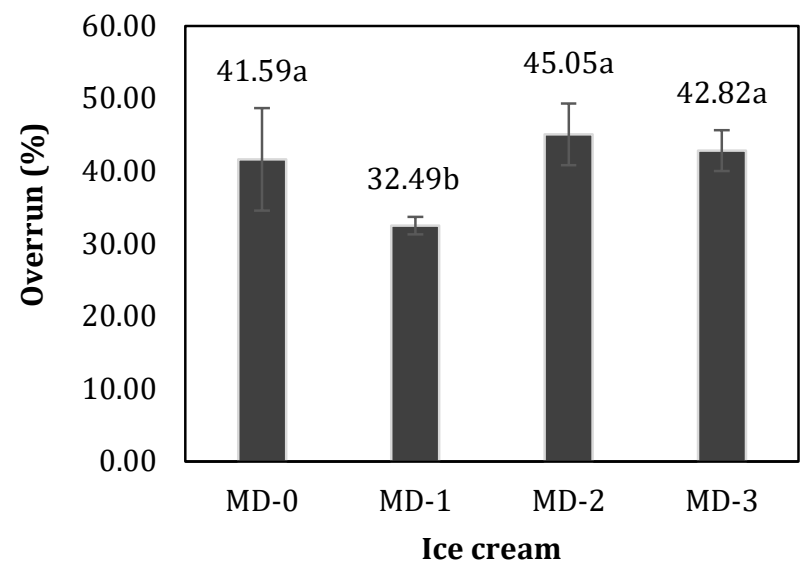

Figure 2. Overrun of canola oil-based ice cream samples formulated by using different amounts of maltodextrin. MD-0, MD-1, MD-2, and MD-3 represent ice creams with $0 \%, 1 \%, 2 \%$ and $3 \%(\mathrm{w} / \mathrm{w})$ maltodextrin, respectively. Data with different letters are significantly different $(\mathrm{p}<0.05)$

Figure 2 shows the percentage of overrun of ice cream samples which significantly increased $(p<0.05)$ from MD-1 to MD-2, while both MD-2 and MD-3 were insignificantly different ( $p>0.05$ ) with each other and with MD-0. This finding also indicated increased in overrun as the amount of fat (i.e. canola oil) decreased. Similar trend was reported in a previous research which mentioned that decreasing level of fat content in an ice cream causes more amount of air that is whipped into the ice cream mixture and thus leads to higher overrun (Rolon, 2017). However, a study done by Schmidt et al. (1993) reported a contrast outcome where higher amount of maltodextrin added decreased the overrun in an ice cream containing milk fat (contain 35\% unsaturated fatty acids) (Lindmark, 2003). Nevertheless, canola oil was used in this study. This oil contains up to $92 \%$ unsaturated fatty acids (Gunstone, 1996) which are easier to be adsorbed at the air-water interface of an emulsion in an ice cream during freezing process, as compared to saturated fatty acids (Eisner et al., 2005). Therefore, the overrun increased as the fat content decreased.

\subsection{Textural property - Hardness}

One of the important physical characteristics of an ice cream is its textural properties which greatly influence the consumers' tendency to buy it. The texture of an ice cream refers to either soft, creamy, or sandy, among others. This study focused on the ice cream's hardness which is defined as the resistance of the ice cream to deformation from an external force. The hardness depends on the ice crystal size and ice phase volume within the ice cream (Muse \& Hartel, 2004).
Fat content plays important role in affecting the hardness of an ice cream product. Generally, if the fat content in an ice cream formulation is reduced, the water content is increased which leads to large ice crystals of greater amount within an ice cream structure and subsequently results in harder ice cream. However, contrast results were obtained in this study. According to Figure 3, sample MD-3 with lowest fat content (2\% $\mathrm{w} / \mathrm{w}$ ) was the softest, while sample MD-1 with highest amount of fat $(4 \% \mathrm{w} / \mathrm{w})$ was the hardest. This finding may be due to addition of maltodextrin in the formulation. Maltodextrin is a gelling agent that can absorb free water in a formulation within an ice cream and can control recrystallization (Regand \& Goff, 2003; Goff, 1997). Furthermore, as the maltodextrin increased, the fat content decreased. Muse and Hartel (2004) and Tharp et al. (1998) reported that destabilized fat forms a network between the air cells in the ice cream; thus, decreased in fat content may decrease the ice cream's hardness. Hardness is also inversely related to the overrun (Muse \& Hartel, 2004; Sofjan \& Hartel, 2004; Wilbey et al., 1998) which justified highest hardness of MD-1 whilst exhibiting the lowest overrun. Despite this finding, there was no significant difference $(p>0.05)$ between all samples in terms of hardness.

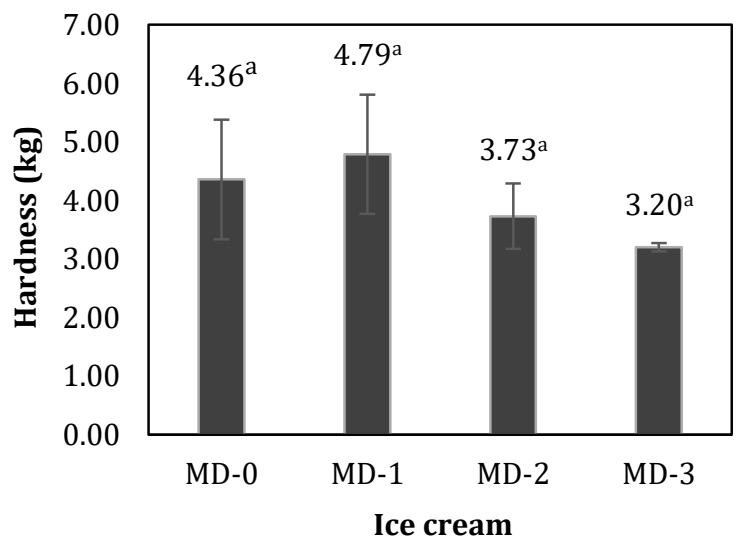

Figure 3. Hardness of canola oil-based ice cream samples formulated by using different amount of maltodextrin; MD-0, MD-1, MD-2, and MD-3 represent ice creams with $0 \%, 1 \%, 2 \%$ and $3 \%(\mathrm{w} / \mathrm{w})$ maltodextrin, respectively

\subsection{Melting rate}

Slow melting rate of an ice cream is highly desirable. Melting rate of an ice cream is affected by many factors, including 1) ingredients; 2) components - an ice cream has three main structural components i.e. air cells, ice crystals, and fat globules which are dispersed in a continuous phase of unfrozen solution (Muse \& Hartel, 2004); 3) The consistency coefficient of the mix; 4) the amount of air incorporated; 5) the nature of the ice crystals, and 6) the network of fat globules formed during freezing (Bahramparvar \& Tehrani, 2011; Muse \& Hartel, 2004).

Figure 4 shows the melting rate of each ice cream formulation which was determined based on the changes in melted ice cream mass $(\% \mathrm{w} / \mathrm{w})$ over time (min). There was no significant difference ( $p>0.05$ ) between MD-0, MD-1, and MD-2 in their melting rates, while MD-3 showed fastest melting rate as compared to other samples which was undesirable. This occurrence may be due to lowest fat content in the MD-3. According to Marshall et al. (2003), melting rate of an ice cream is highly contributed by fat destabilization. Fat globules function in covering and maintaining the air cells in an ice cream. These fat globules form chains which build a fat network and further stabilize the air bubbles in the ice cream structure, thus leads to 
slower melting rate. Bolliger et al. (2000) also found that ice creams with higher level of destabilized fat had slower melting rates. The high levels of destabilized fat assist in maintaining the shape of the ice cream during melting, and the fat network within the ice cream helps in retaining the ice cream on the screen (Bolliger et al., 2000; Tharp et al., 1998).

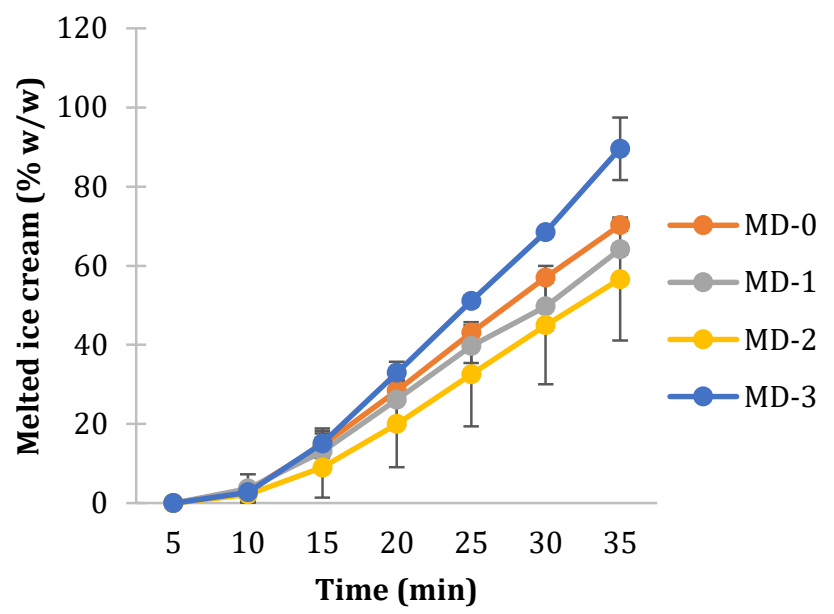

Figure 4. Melting rate of canola oil-based ice cream samples formulated by using different amount of maltodextrin; MD-0, MD-1, MD-2, and MD-3 represent ice creams with $0 \%, 1 \%, 2 \%$ and $3 \%(\mathrm{w} / \mathrm{w})$ maltodextrin, respectively

The fastest melting rate of MD-3 was in line with Roland et al. (1999) which reported that the use of maltodextrin increased the melting rate of an ice cream product. Addition of maltodextrin leads to greater air incorporation in an ice cream, and the air bubbles were more finely dispersed (Flores \& Goff, 1999). Zhang \& Goff (2005) also found that addition of maltodextrin increased air bubble stability by supporting partial coalescence of fat globules. However, too much partially coalesced fat globules may cause unstable air bubbles. Therefore, it is of great importance to determine the suitable amount of maltodextrin to be added in an ice cream formulation as a fat replacer. It can be concluded from Figure 4 that the addition of maltodextrin can potentially decreased the melting rate, yet up to $2 \%(\mathrm{w} / \mathrm{w}$ ) only. According to Sakurai et al. (1996), an ice cream's melting rate is also affected by its overrun. Ice creams with high overrun melt slowly and had good melting resistance as a result of air bubbles within the ice cream which are heat resistance from the environment (Sofjan \& Hartel, 2004).

\section{Conclusion}

For the canola oil-based ice cream samples, increased in the amount of maltodextrin (i.e. decreased in fat content) contributed to significant increase $(p<0.05)$ in overrun, yet did not significantly affect the hardness. Both MD-3 and MD-2 showed fastest and slowest melting rate, respectively. In overall, the most acceptable ice cream sample was MD-2 which exhibited high overrun ( $43.16 \pm 1.13 \%)$, soft texture $(3.73 \pm 0.75$ $\mathrm{kg}$ ), and slowest melting rate. These findings highlighted the potential of a canola oil-based ice cream with added MD to be proposed to the industry. Further studies are highly recommended in determining the consumers' acceptability by conducting sensory evaluation. Additionally, changes in ice cream's flavour and textural properties as affected by different storage conditions may also be investigated.

\section{Acknowledgment}

The authors would like to acknowledge the Faculty of AgroIndustry, Kasetsart University, Thailand for allowing Miss Nirada Thirathummacoup to conduct this project at the Faculty of Food Science and Technology, Universiti Putra Malaysia, Malaysia.

\section{Author contributions}

Nirada Thirathummacoup: Methodology, data curation, writing. Rozzamri Ashari: Review and editing the manuscript. Masni Mat Yusoff: Conceptualization, methodology, data curation, review and editing the manuscript, supervision and project administration.

\section{Conflict of interests}

The authors declare that they have no competing financial interest or personal relationships that could have appeared to influence the work reported in this paper.

\section{References}

Akbari, M., Eskandari, M. H., \& Davoudi, Z. (2019). Application and functions of fat replacers in low-fat ice cream: A review. Trends in Food Science \& Technology, 86, 3440.

Bahramparvar, M., \& Tehrani, M. M. (2011). Application and functions of stabilizers in ice cream. Food Reviews International, 27(4), 389-407.

Bayourthe C., Enjalbert F., \& Moncoulon R. (2000). Effects of different forms of canola oil fatty acids plus canola meal on milk composition and physical properties of butter. Journal of Dairy Science, 83(4), 690-696.

Biasutti, M., Venir, E., Marino, M., Maifreni, M., \& Innocente, N. (2013). Effects of high pressure homogenisation of ice cream mix on the physical and structural properties of ice cream. International Dairy Journal, 32(1), 40-45.

Bierenbaum, M. L., Reichstein, R. P., Watkins, T. R., Maginnis, W. P., \& Geller, M. (2013). Effects of canola oil on serum lipids in humans. Journal of the American College of Nutrition, 10(3), 228-233.

Bolliger, S., Goff, H. D., \& Tharp, B. W. (2000). Correlation between colloidal properties of ice cream mix and ice cream. International Dairy Journal, 10(4), 303-309.

Eisner, M. D., Wildmoser, H., \& Windhab, E. J. (2005). Air cell microstructuring in a high viscous ice cream matrix. Colloids and Surfaces A: Physicochemical and Engineering Aspects, 263(1-3), 390-399.

Erkaya, T., \& Mustafa, S. (2012). Influence of cape gooseberry (Physalis peruviana L.) addition on the chemical and sensory characteristics and mineral concentrations of ice cream, 45, 331-335.

Flores, A. A., \& Goff, H. D. (1999). Ice crystal size distribution in dynamically frozen model solutions and ice cream as affected by stabilizers. Journal of Dairy Science, 82, 1399.

Goff, H. D. (1997). Colloidal aspects of ice cream-A review. International Dairy Journal, 7, 363-373.

Gunstone, F. D. (1996). Fatty acid and lipid chemistry (pp. 2-3). United States: Springer.

Gunstone, F. D., \& Padley, F. B. (2018). Ice Cream. In Lipid Technologies and Applications (pp. 35-51). Routledge: CRC Press.

Grossi, M., Lazzarini, R., Lanzoni, M., \& Riccò, B. (2011). A novel technique to control ice cream freezing by electrical 
characteristics analysis. Journal of Food Engineering, 106(4), 347-354.

Hedayatnia, S., Mirhosseini, H., Amid, B. T., Sarker, Z. I., Kostadinović, S. K., \& Karim, R. (2016). Effect of different fat replacers and drying methods on thermal behaviour, morphology and sensory attributes of reduced-fat coffee creamer. LWT-Food Science and Technology, 72, 330-342.

Jimenez-Florez, R., Klipfel, N. J., \& Tobias, J. (1993). Ice cream and frozen desserts. In Dairy Science and Technology Handbook: Product Manufacturing (Vol. II) (pp.57). New York: Wiley.

Karaca, O. B., Güven, M., Yasar, K., Kaya, S., \& Kahyaoglu, T. (2009). The functional, rheological and sensory characteristics of ice creams with various fat replacers. International Journal of Dairy Technology, 62(1), 9399.

Kurt, A., Cengiz, A., \& Kahyaoglu, T. (2016). The effect of gum tragacanth on the rheological properties of salep based ice cream mix. Carbohydrate Polymers, 143, 116-123.

Lu, J., Pua, X., Liu, C., Chang, C., \& Cheng, K. (2014). The implementation of HACCP management system in a chocolate ice cream plant. Journal of Food and Drug Analysis, 22(3), 391-398.

Marshall, R. T., Goff, H. D., \& Hartel, R. W. (2003). Ice Cream (6th ed.). New York: Kluwer Academic Press.

Muse, M. R., \& Hartel, R. W. (2004). Ice cream structural elements that affect melting rate and hardness. Journal of Dairy Science, 87(1), 1-10.

Regand, A., \& Goff, H. D. (2003). Structure and ice recrystallization in frozen stabilized ice cream model systems. Food Hydrocolloids, 17(1), 95-102.

Roland, A. M., Phillips, L. G., \& Boor, K. J. (1999). Effects of fat replacers on the sensory properties, color, melting and hardness of ice cream. Journal of Dairy Science, 82, 2094-2100.

Roller, S., \& Jones, S. A. (1996). Handbook of fat replacers (pp. 99-118). Boca Raton: CRC Press.

Rolon, M., Bakke, A. J., Coupland, J. N., Hayes, J. E., \& Roberts, R. F. (2017). Effect of fat content on the physical properties and consumer acceptability of vanilla ice cream. Journal of Dairy Science, 100(7), 5217-5227.

Sakurai, K., Kokubo, S., Hakamata, K., Tomita, M., \& Yoshida, S. (1996). Effect of production conditions on ice cream melting resistance and hardness. Milchwissenschaft Milk Science International, 51(8), 451-454.

Schmidt, K. A., Lundy, A., Reynolds, J., \& Yee, L. N. (1993). Carbohydrate or protein-based fat mimicker effects on ice milk properties. Journal of Food Science, 58(4), 761-763.

Sofjan, R. P., \& Hartel, R. W. (2004). Effects of overrun on structural and physical characteristics of ice cream. International Dairy Journal, 14, 255-262.

Soukoulis, C., Chandrinos, I., \& Tzia, C. (2008). Study of the functionality of selected hydrocolloids and their blends with $\kappa$-carrageenan on storage quality of vanilla ice cream. LWT-Food Science and Technology, 41, 1816-1827.

Soukoulis, C., Rontogianni, E., \& Tzia, C. (2010). Contribution of thermal, rheological and physical measurements to the determination of sensorially perceived quality of ice cream containing bulk sweeteners. Journal of Food Engineering, 100(4), 634-641.

Tharp, B. W., Forrest, B., Swan, C., Dunning, L., \& Hilmoe, M. (1998). Basic factors affecting ice cream meltdown. In Ice Cream (pp. 54-64). Proceeding of the International Symposium, Athens, Greece.

Wilbey, R. A., Cooke, T., \& Dimos, G. (1998). Effects of solute concentration, overrun and storage on the hardness of ice cream. In Ice Cream (pp. 186-187). Proceeding of the International Symposium, Athens, Greece.

World Health Organization (2015, 2013). Accessible from: https://www.who.int/internal-publicationsdetail/healthy-diet-factsheet394. Retrieved on 26 March 2020.

Zhang, Z., \& Goff, H. D. (2005). On fat destabilization and composition of the air interface in ice cream containing saturated and unsaturated monoglyceride. International Dairy Journal, 15, 495-500. 